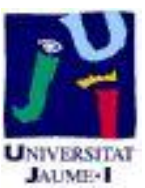

Título artículo / Títol article: Developing Moral Sensitivity Throgh Protest Scenarios in International NGDOs' Communication

Autores / Autors

Pinazo Calatayud, Daniel ; Nos Aldás, Eloísa

Revista:

Communication. Communication Research, 2013

Versión / Versió:

Preprint del autor

Cita bibliográfica / Cita bibliogràfica (ISO 690):

url Repositori UJI:
CALATAYUD, Daniel Pinazo; ALDAS, Eloísa Nos. Developing Moral Sensitivity Through Protest Scenarios in International NGDOs' Communication. Communication Research, 2013, p. 1-24

http://hdl.handle.net/10234/86989 


\title{
Developing Moral Sensitivity through Protest Scenarios \\ in International NGDOs' Communication
}

\author{
Daniel Pinazo Calatayud (pinazo@psi.uji.es) \\ Eloísa Nos Aldás (aldas@com.uji.es)
}

\begin{abstract}
This paper studies advertising campaigns of NGDOs by applying the innovative concepts of protest communication scenarios and moral sensitivity. Its main purpose is to advance current understanding on how two conceptually different communication scenarios -donor and protest- impact the social engagement of the public. The interdisciplinary methodology combines a discursive and psychological perspective with an empirical survey study designed with the support of cultural discourse analysis (Hall, 1997). The findings demonstrate that using communication models based on the need for collective help for poverty in terms of an unjust situation -what we call a protest communication model- increases moral sensitivity and, therefore, social action. These results are of interest for planning and assessing the organizational communication of NGDOs designed from their educational and social action liabilities. This research shows that utilizing these criteria increases the efficacy of their communication in awareness raising and social engagement without being detrimental to funding amounts.
\end{abstract}

Keywords: communication scenario, moral sensitivity, NGO, development, poverty, discourse, protest, donation, efficacy, awareness, engagement 
One priority of the advertising campaigns of international Non-Governmental Development Organizations (NGDOs) is to raise sensitivity about the moral need to help eradicate world poverty (Cohen, 2001; DEEEP, 2006; Malhotra, 2000; Smith, 2004b; 2008). In the area of solidarity for development, raising sensitivity means raising audience awareness of the moral need to act in order to help eliminate poverty (Haidt, 2001; Moll, Oliver-Souza, Garrido, Bramati, Caparelli-Daquer, Paiva, Zahn, Grafman, 2007; Narvaez \& Rest, 1995). However, international NGDOs rely heavily on donor communication scenarios to accomplish their missions. The latest findings from moral neuroscience reveal that this dominant discourse in their advertising, based on the donor dilemma, is very limited in its capacity to raise awareness either emotionally or cognitively (Greene, Sommerville, Nystrom, Darley, \& Cohen, 2001; Greene, 2003). The lack of efficacy of the communication of NGDOs is a recurrent theme in the main specialized literature of this field of study, which highlights the urgent need to analyze the cultural consequences of these discourses, particularly due to the fact that their ambiguity entails "an encroaching skepticism and disengagement" (Smith, 2004a, p. 148).

This article explores the most suitable communication scenarios for activating a moral sensitivity in the receivers. A message that raises moral sensitivity is a message that prompts emotional reactions together with a concomitant moral judgment. Moral judgments establish which social behaviors are considered acceptable or not. Therefore, we understand moral sensitivity as the individual's capacity to detect and interpret moral questions (Haidt, 2001; Moll, Garrido, Bramati, Caparelli-Daquer, Paiva, \& Zahn, 2007). Furthermore, from a communicative perspective, we mean it to be a network of emotions and beliefs that activate behaviours of social helping. This ability is critical to social behavior, particularly when 
oriented to eradicate world poverty (Pinazo, Barros-Loscertales, Peris, Ventura, \& Avila, 2012).

(Figure 1 here)

The communication strategies used by many of the large international NGDOs tend to emphasize the role of the suffering of the other (communication scenario based on the donor dilemma) and leave to one side any social condemnation of the conditions that cause the suffering (Benthall, 2010; CONCORD, 2007; General Assembly of European NGOs, 1989; Nos Aldás \& Pinazo, 2010; Sogge, 1996).

Recent studies on moral sensitivity have shown that the donor dilemma can prompt an impersonal emotional response; the potential donor feels that denying help does not imply a moral breach of the norm to assist those who depend on his or her help (Greene et al., 2001; Greene, 2004). In these impersonal dilemmas not helping is judged to be more permissible than in personal moral dilemmas. The donor approaches the suffering of the other as a cognitive problem (the donor helps just to get rid of a feeling of guilt) in impersonal dilemmas. However, in a personal moral dilemma, both emotions and beliefs interact, and the donor acts because he or she wants to be part of an effective social solution.

Both suffering and condemnation of the conditions that generate and perpetuate poverty are relevant factors in raising moral sensitivity to help eradicate poverty (CONCORD 2004, 2007; Minear, 1987; Tallon, 2008) (Note 1). As such, we find that people with moral sensitivity offer emotional responses related to guilt, compassion and indignation and cognitive responses linked to injustice and moral judgment (moral/immoral). These responses motivate behaviors that lead to social action 
Approaching the appeal for social help to eradicate poverty from the position of a social condemnation dilemma (protest scenario) may have a more intense impact on the moral emotions of perception of suffering and condemnation than the donor dilemma approach (donor scenario). This more intense impact would be possible if moral sensitivity is activated. In this model, the emotional responses of guilt and compassion (present in the donor communication scenarios) are accompanied by the emotional response of indignation, which is associated with a judgment of condemnation for the social injustice of poverty and the immorality of not acting to abolish it. This is only possible by approaching the root "structural and systemic" causes of poverty (Cohen, 2001, p.178) (Figure 2).

(Figure 2 here)

Nevertheless, the role of social condemnation of poverty has not been widely explored in the study of communication strategies for social causes (Smith, 2004a; 2004b). The aim of this work is to advance current understanding by addressing how these two conceptually different communication scenarios of NGDOs -donor and protest- impact moral sensitivity to helping. In other words, it analyzes the capacity of messages focusing on social condemnation to raise moral sensitivity (an emotional and cognitive response that leads to certain behaviors) to the suffering of others.

\section{The Discourse on the Suffering of the Other (Donor Scenarios)}

One of the main functions of an advertisement to encourage helping is to raise public awareness of the injustice of poverty. As public messages, the communication strategies of NGDOs have the capability of morally developing society and enhancing people's quality of life (Sen, 1999). Thus, the agents of publicity for social causes (in the present paper, 
international NGDOs as civic actors) need to be persuasive both to raise funds through donations and to raise public awareness of the need to help unknown others by addressing the root causes of that suffering. However, the growing need to raise funds has led many NGDOs to focus their publicity campaigns solely on the perception of suffering, thereby establishing a compassionate moral judgment on poverty (Benthall, 1995; Deacon, 1999; DEEEP, 1989; 2006; Dogra, 2007). The most widespread feature of this type of message is the pursuit of an emotional impact based solely on compassion, which has added to the problem of “compassion fatigue" (Moeller, 1999) and a "crisis of pity" (Boltanski, 1999; Vestergaard, 2008).

In these donor communication scenarios, the perception of suffering triggers compassion (Haidt, 2003). The communication strategy presents the public with a moral dilemma in which they have to decide whether or not to donate their money to an NGDO so that it can take responsibility for alleviating the suffering of anonymous distant others (Black, 1992; Eade, 1995). Compassion motivates the donor to alleviate the suffering he or she perceives (Davidson \& Harrington, 2002). This usually conditions altruistic behaviors towards a victim (Haidt, 2003; Sturmer, Zinder, \& Omoto, 2005).

Nonetheless, previous research suggests that focusing the communication strategy on the perception of suffering might not have the desired emotional impact, if it hopes to raise moral sensitivity in its audience (Greene et al., 2001; Greene, 2004). The weakness of donor scenarios in relation to the liabilities of the communication of NGDOs can be explained by various factors. First, the insistence on compassionate messages, together with the idea that any action of solidarity has to be delegated to the NGDO as an intermediary, can reduce personal involvement in the relief of suffering. In a moral judgment on whether to help distant third parties (anonymous members of an out-group), the emotional distance from those suffering poverty increases. Therefore, communicating with the public through messages 
focused on making them feel the need to alleviate their feeling of guilt merely transforms the act of donating into a problem to solve (something impersonal), rather than a moral personal question (Pinazo et al., 2012). The more we insist on these models, the more accustomed we become to the suffering of others and to placing the responsibility for addressing it in the hands of an intermediary.

Second, in the donor scenario, the appeal for help engenders a feeling of guilt if help is not given. The donor scenario requests help to mitigate the suffering of anonymous people. Failing to help can generate an unpleasant feeling of guilt; the individual is performing an action that results in the suffering of the other, which is not morally acceptable (Greene, 2004; Baumeister, Stillwell, \& Heatherton, 1994; Lazarus, 1991). Guilt is a self-conscious moral emotion that involves a thought of responsibility for harming the other (Lazarus, 1991). The person is aware of his or her responsibility in a moral transgression that harms others if he or she does not do the right thing (Baumeister et al., 2004; Lazarus, 1991). The desire to reduce this unpleasant emotional state can deflect the cognitive resources (the attention) needed to judge the appropriate behaviors to eradicate poverty. The emotion of guilt is associated with pro-social behavior, but specifically with the motivation to offer charitable help (Basil, Ridgway, \& Basil, 2008; Lindsey, 2005). The donor scenario message focuses attention on charity as a solution, providing a good way for the potential donor to alleviate his or her uncomfortable guilt emotion and to avoid any further involvement in the problem; hence, it has not proved effective for eradicating poverty (Darnton \& Kirk, 2011).

However, guilt, as cognition, can be channeled to alternative emotions, not necessarily limited to guilt, expanding responsibility. The motivation to help associated with guilt can be either the emotion of compassion or that of indignation (Haidt, 2003; Hoffman, 2000). Research into moral emotions suggests that the perception of the violation of moral rules 
provokes disgust or indignation, thus enhancing moral sensitivity (Haidt, 2003; Rozin, Haidt, \& McCauley, 2005; Rozin, Lowery, Imada, \& Haidt, 1999).

Indignation has not usually been taken into account in communication strategies appealing for aid. Instead, they have predominantly focused on emotions of guilt or compassion (e.g. Basil, Ridgway, \& Basil, 2006; 2008). The current dominant donor communication scenario has created a mental model in the population that activates the emotions of guilt and compassion in order to foster cooperation with NGDOs. However, indignation is also an emotion that is present in the perception of the problem raised by social poverty and is linked to the awareness of social injustice / social justice. Therefore, activating a representation of the image of poverty based on indignation may broaden the mental model citizens have about the ways of eradicating poverty.

This research proposes that an effective way of achieving a constructive activation of indignation as part of the mental model of poverty is through communication scenarios based on the condemnation of poverty. Such a communicative model -protest scenarios- may raise moral sensitivity by connecting the social emotions of guilt, compassion and indignation with beliefs of injustice and immorality in the social imaginary of poverty. As argued above, it is our view that certain communication scenarios may induce moral sensitivity by combining compassion with the feeling of indignation and the judgment of immorality and injustice, thereby reinforcing social development towards helping behaviors and social action.

\section{The Discourse on the Social Condemnation of Poverty (Protest Scenarios)}

Communication designed to attract aid for development sets out to motivate the public to donate money to the very causes supported and defended by NGDOs. These causes are explained by the social injustices that underlie their origins. However, insisting on appeals for compassion has pushed the condemnation of the social injustice of poverty into a subordinate 
position. A discourse that activates the emotion of indignation by condemning the situation focuses attention more strongly on the moral breach that causes the recipients' suffering (Batson et al., 1995). As a result, social condemnation does not prevent compassion from being activated, but rather adds value in a message that appeals for solidarity. Moral sensitivity may be strengthened if the feeling of guilt, or the appeal to carry out some kind of helping action, includes moral emotions of compassion and condemnation, such as indignation.

Campaigns to eradicate world poverty present a "collective help dilemma" to the audience (Green, 2001). This means that we feel indignant when the norms affecting the shared rules of a reference group are violated, since this action is perceived as a social injustice. However, we can also feel indignant if this injustice affects third parties, even if they are anonymous, distant and not part of our reference group. In addition, we can feel guilty for the responsibility of harm we ourselves have not caused if we consider that our own reference group can have some involvement in the problem, either because it has acted to create the conditions for poverty or because it has not acted to prevent these conditions from occurring (Branscombe, 2004; Branscombe, Doosje, \& McGarty, 2002; Wohl \& Branscombe, 2008).

When a donation has only been solicited by direct guilt, the person avoids the moral condemnation of the causes of poverty, particularly if he or she bears some feeling of involvement with it. In contrast to this donor scenario, the protest scenario provides a communication structure in which the audience judges that a moral norm is being violated in a certain situation (Note 2). In this way, the audience can assess their own participation in the injustice and the possibility of acting to resolve the problem by pressing the liable agents to prevent the conditions that lead to the problem. As previous research has demonstrated, this is even more so if these liable agents are part of the audience reference group (Branscombe, 
2004; Branscombe, Doosje, \& McGarty, 2002; Wohl \& Branscombe, 2008). These judgments will be associated with emotions of condemnation such as indignation over the harm caused, without impeding compassion for the suffering.

Emotions of condemnation like indignation are critical in the response to the breach of moral norms (Haidt, 2003). They arise when the moral codes affecting the community are violated. These emotions tend to lead to action by inducing pro-social responses, such as helping others (Haidt, 2003; Moll, de Oliveira-Souza, Moll, \& Ignacio, 2005). Therefore, the activation of social norms should intensify the moral sense and the injustice of the situation. However, in order for a pro-social response to occur, such as a donation or the moral condemnation of the situation, the social norm transgressed must be salient (Schwartz, 1977).

The donor scenario does not emphasize the condemnation of the moral violation of the social norms that are at the bottom of the structural causes of poverty. Hence, it will not activate the perception of social injustice and the violation of the moral norm with sufficient intensity to activate moral emotions of condemnation like indignation or anger. This communication strategy, therefore, inhibits moral sensitivity rather than strengthening it (Silverstone, 2008). This is the reason why, in donor scenarios, moral sensitivity is less representative of the process that leads to the response of social action. It is possible to raise audience sensitivity by encouraging the perception that the situation of poverty is socially unjust and immoral. In order to do so, it is necessary to construct the image of poverty based on the idea of interdependence (moral relations), rather than dependence (charity). This emphasis activates the motivation to condemn poverty by highlighting the personal involvement of the audience and accentuating the harm caused by not doing the right thing to eradicate it.

Previous research has also demonstrated that the mere presence of others can serve to activate moral norms (e.g., Herman, Roth, \& Polivy, 2003). A norm which is a feature of the 
mental model of citizenry can be activated when one person sees another person respecting it. If the demand for condemnation of suffering is presented as a norm, individuals feel engaged and assume the need to act pro-socially by condemning the situation, since they are more sensitive to poverty. A collective help scenario capable of personally involving the donor as an active agent in the solution of the problem requires a communicative structure that activates concomitant mental models, incorporating all of these emotions and beliefs for moral sensitivity. Therefore, if no help is given, the perception of social injustice together with the perception of immorality are affected by emotions of guilt, compassion and indignation involved in the situation.

\section{The Study: Protest Scenarios to Overcome the Limitations of Donor Scenarios}

In the first place, the present study proposes an alternative communication model based on moral sensitivity in order to cultivate social action. We advance a communication model that morally sensitizes the receivers. This model suggests that the pillars of moral sensitivity are social emotions and the beliefs of injustice and immorality. Furthermore, these mental relations are very likely to activate protest and social action to reduce poverty. In the second place, this study proposes an alternative communication strategy based on the social condemnation of poverty, as a possible communication scenario to raise moral sensitivity in the target audience. By representing an alternative image of poverty, we suggest that protest scenarios can trigger moral sensitivity, the interaction among these emotions of guilt, compassion and indignation and the beliefs of immorality and injustice. This moral sensitivity positions social emotions and judgments as activators of protest beliefs, without being detrimental to the capacity to activate donation behaviors. Thus, social action would be motivated by both cognitive and emotional responses (Figure 3). 
(Figure 3 here)

The protest scenario communication strategy we propose for NGDOs is grounded on a message of social condemnation of the causes of poverty. This protest scenario model suggests that presenting the need for collective help for poverty in terms of an unjust situation will generate more intense emotional responses of compassion and indignation by also activating the perception of immorality. By highlighting the violation of a moral norm in situations that we perceive as immoral or unjust, we assert that the protest scenario will have a more intense effect on the emotional and cognitive response. The protest scenario poses the moral problem of helping to eradicate poverty from its very roots. In this scenario, the message advocates protesting about situations of social injustice. The emotional response is expected to be one of compassion and indignation. The donor must understand that maintaining the forms of behaviour that perpetuate poverty is immoral and unjust. A communicative strategy based on this type of scenario, where moral sensitivity is raised, can contribute a greater personal involvement to the mental construction of the image of poverty (Pinazo et al., 2012).

The aim of this study was, first, to test the distinct capacity of donor and protest communication scenarios to trigger moral sensitivity to poverty among those surveyed, and, second, to test the moral sensitivity communication model itself (Figure 1 and 2). In order to test this model, we took into consideration social emotions like guilt, compassion and indignation and protest beliefs such as the immorality and the injustice of poverty. The interaction of these responses was generated by a communication strategy of protest rather than a donation strategy. This model was based on the assumption that both types of responses -emotional and cognitive- would have a differential impact on distinct social 
actions. On the one hand, we tested the effect on the behavior of monetary donation and on the other the intention to participate in social protest actions (as presented in Figure 3).

In order to test this communication model, we designed the following study based on 7 hypotheses extracted from the conceptual and methodological framework developed in the previous epigraphs.

H1. Protest appeals will generate a stronger emotional response of condemnation (involving indignation) than donation appeals.

H2. Protest appeals will generate a stronger emotional response of compassion than donation appeals.

H3. Protest appeals will generate a stronger moral judgment to help than donation appeals (led by the immorality of not helping).

H4. Protest appeals will generate a stronger sense of social injustice about poverty than donation appeals.

H5. Protest appeals will generate a stronger willingness to engage in donation than donation appeals.

H6. Protest appeals will generate a stronger willingness to engage in protest actions.

H7. The model for raising moral sensitivity will better fit the data in the context of the protest scenario rather than that of the donor scenario, regardless of the affected social action (to donate or protest).

\section{Method}

\section{Procedure}

This study is based on field research that recreated donor and protest communication scenarios in order to analyze the role of moral sensitivity. The materials used were designed with the following discursive structure (see Appendix 1 and Appendix 2): 
Messages A (donor scenario): a) The sender (an NGDO) states a general/impersonal dramatic situation referring to "them" (the "other," the "poor"), b) offers itself to play the role of the mediator and c) asks for economic support from the donors.

Messages B (protest scenario): a) The message emphasizes indignation, b) condemns a specific unfair/inhuman situation and c) encourages the receiver to protest.

Twelve scripts (action scenarios) were created following these two models to elicit the experience of the link between collective help scenarios ( 6 protest scripts and 6 donor scripts) and moral emotions. The donor scripts were prepared from an initial analysis of large NGO advertising campaigns (e.g., Amnesty International, UNICEF, Manos Unidas, Médecins Sans Frontières, Intermón Oxfam). The protest scripts were elaborated from public condemnations of the actions of transnational corporations in their market activities (Werner \& Weiss, 2003). Based on an initial behavioral study, a total of 23 volunteers and/or professionals working in cooperation were asked to determine the category (donor or protest) to which each of the scripts belonged (see Appendix1). The panel reached a unanimous decision on the classification of 11 of the 12 scripts. In these cases, the scripts that we thought evoked the donor dilemma and those that evoked the protest dilemma were categorized as such. Only two subjects classified one script of the protest category as a donor dilemma, although the rest of the group considered it as a protest dilemma.

(Appendix1here)

Based on these scripts, a structured questionnaire was designed in the following way (See Appendix 2):

1. An image of poverty; 
2. This image was followed by one of the twelve selected scripts accompanied by the question "How do you feel about the situation?"

3. Respondents were then asked to answer the previous question according to the following adjectives describing an emotion: "compassionate," "guilty," "indignant;"

4. Two questions were asked about the degree of morality and/or social justice of the situation of poverty: a. "Do you think it is immoral not to help eradicate world poverty?;" b. "Do you think it is a social injustice that poverty exists in the world?"

5. Finally, respondents were asked about their willingness to donate money to an NGDO and their willingness to participate in protest actions against poverty organized by an NGDO. All questions were answered on a scale of 1 to 7 .

After faculty and students allowed permission for the study, we explained the research to them and distributed the questionnaire in class to the university students. Each student answered a single questionnaire. The twelve scripts were distributed randomly among them.

\section{(Appendix 2 here)}

\section{Sample}

290 undergraduates (182 females; mean age $=23.70$; range 18-45) were studied, each having given prior informed consent. 140 undergraduates responded to the donor scenario scripts; 150 undergraduates responded to the protest scenario scripts. All the subjects in this sample were selected on the basis that they did not collaborate with any NGO or NGDO at the time of the survey. 
Results

The correlation of the variables of the sample is presented in Table 1. Hypotheses 1 to 6 were tested with ANOVA (Table 2).

(Table 1 here)

The results reflect that hypothesis 1, 3, 4 and 6 have been confirmed (as can be seen in Table 2). Active protest communication scenarios increase condemnation emotions such as indignation (H1) and beliefs of immorality (H3) and injustice (H4) for poverty situations more effectively than donor scenarios. The people who participated in the survey considered that the situations were unjust and that not acting to prevent them was immoral, whatever the type of communication scenario. They also expressed their will to engage in protest actions. However, the perception of immorality and injustice and the willingness to engage in protest actions was significantly higher in the protest scenarios (Table 2).

(Table 2 here)

Indignation and the aforementioned beliefs form the core of moral sensitivity. Protest scenarios as a communicative strategy do not improve the capacity to promote compassion and guilt. Instead, they add the emotion of condemnation and the perception of injustice and immorality to this model, broadening the moral sense of the image of poverty. On the contrary, the donor scenario does not increase any of these emotions and beliefs analyzed. Although there are no significant differences between scenario types in the activation of the emotion of guilt, in the protest model guilt shows the lowest intensity. Regarding compassion (hypothesis 2), people feel compassionate when viewing the scenarios presented. No 
differences were noted between the types of scenario or between the two scenarios in the activation of the donation response (hypothesis 5).

To test hypothesis 7 we used a structural equation modeling test for each communication scenario (donor scenario and protest scenario) and each social action (donation or protest) (Figure 3). We used the EQS 6.1. for Windows Software. We tested the effect of communication scenarios on moral sensitivity in four possible models: a) donor scenario/donation social action; b) donor scenario/protest social action; c) protest scenario/donation social action; d) protest scenario/protest social action.

(Figure 3 here)

In total, each model tested included a maximum of 14 free parameters (Note 3 ). In this regard, none of the models tested produced a good fit chi-square index. The donor-protest action model produced a poor fit chi-square statistic $\chi^{2}(21, \mathrm{~N}=140)=115.47, \mathrm{p}<.01$. The donor-donor action model produced a poor fit chi-square statistic as well: $\chi^{2}$ $(21, \mathrm{~N}=140)=115.47 \mathrm{p}<.01$. The models derived from the protest scenario also produced a bad fit chi-square statistic, both for the donor action $\chi^{2}(15, \mathrm{~N}=150)=68.47, \mathrm{p}<.01$ and for the protest action: $\chi^{2}(15, \mathrm{~N}=150)=72.81, \mathrm{p}<.01$.

Nonetheless, the goodness of fit $\chi^{2}$ in itself is insufficient to set the value of a model. The goodness of fit $\chi^{2}$ is particularly sensitive, not only to sample size, but also to the complexity of the model (Barret, 2007; Bentler \& Bonnet, 1980; Jöreskog \& Sörbom, 1993). This is why it was necessary to supplement the interpretation of the data with other statistics. $\mathrm{Hu}$, Bentler and Kano (1992) propose taking alternative statistics into account and offer criteria to establish the cut-off point to assess the model fit. Specifically, indexes such as the NFI (Bentler-Bonett Normed Fit Index) or the CFI (Comparative Fit Index), in conjunction 
with RMSEA (Root Mean Square of Approximation), offer a good combination of fit indexes to determine the best fit of a structural model to the data. Hu and Bentler (1999) suggest that the NFI and the CFI indicate a good fit with values higher than .90, while the RMSEA should give a value close to .08 .

Applying these criteria to the chi-square results, the donor/donor solution $(\mathrm{CFI}=.64$;

$\mathrm{NFI}=.65 ; \mathrm{RMSEA}=.186(90 \% \mathrm{CI}=.133, .243)$ and the donor/protest solution $(\mathrm{CFI}=.75$,

$\mathrm{NFI}=.73 ; \mathrm{RMSEA}=.157(90 \% \mathrm{CI}=.103, .215)$ demonstrated a poor fit. In the protest scenario model, the solutions better reflected the data. The protest/donation solution showed a good fit $(\mathrm{CFI}=.89 ; \mathrm{NFI}=.90 ; \mathrm{RMSEA}=.196(90 \% \mathrm{CI}=.077, .346)$ as well as the protest $/$ protest solution $(\mathrm{CFI}=.90 ; \mathrm{NFI}=.91 ; \mathrm{RMSEA}=.196(90 \% \mathrm{CI}=.077, .346)$. The diagrams of the two protest scenarios are presented below in Figure 4 (donor action) and Figure 5 (protest action). In the diagrams, we have indicated only the parameters of the model that show statistically significant paths (for easier reading of the results).

(Figure 4 here)

(Figure 5 here)

Therefore, hypothesis 7 has also been confirmed by the data. Moral sensitivity is more clearly activated in protest communication scenarios than in donor communication scenarios. The structure of relationships that is reflected in the tested communication model diagram confirms the important role that the network of emotions and beliefs plays in constituting moral sensitivity. The communication model based on donor scenarios does not adequately reflect the link between social emotions, beliefs, social protest and social action. In the context of the protest scenarios, the model best fits the data. The results reveal the links 
among the different factors of awareness raising for social action, suggesting that the relationships of emotional and cognitive variables with social action varied according to the type of action.

\section{Discussion}

This paper aimed to analyze the failure of the promotional communication of NGDOs in raising awareness about the necessary collective social action to end poverty. We also set out to provide deeper insight into how to reinforce their protest efficacy through moral sensitivity without lowering their donations. On the one hand, the protest scenario demonstrates a higher influence in increasing emotions of condemnation, without being detrimental to the activation of the emotions of compassion and guilt. On the other hand, the protest scenario clearly appears more relevant than the donor scenario because it activates the beliefs of injustice and immorality of collective poverty. In addition, the protest scenario shows a stronger willingness in the respondents to engage in protest actions. The results support our thesis that the creation of communication scenarios by NGDOs based on social condemnation increases moral sensitivity to poverty. By incorporating the emotion of indignation in the response, as well as the beliefs of injustice and immorality, the message emotionally elicits a commitment from the person to condemn the situation.

In addition, in the tested communication model, the results show that the protest scenario fits a communication reaction that links moral sensitivity to a social action, in both the donation and protest models. The findings indicate that communication strategies based on the social condemnation of poverty can be similarly effective for funding, while simultaneously raising moral sensitivity in the audience and adding reactions such as protest to the communication process. This implies that it may be possible to explore alternative models of communication lacking in the dominant donor scenario. Moreover, the findings 
suggest that the donor scenario may be useful for raising moral sensitivity if based on different discourses. Therefore, we propose that further efforts combine donor scenarios with the intensification of moral sensitivity, rather than focusing solely on arousing feelings of guilt.

When analyzing the most significant parameters of the model, we note that the emotion of guilt remains relevant to the perception of poverty and the action generated to eradicate it. However, guilt appears to be an emotion that acts fundamentally on behavior and not on protest beliefs, reflecting its limited capacity to raise awareness on its own. The emotion of indignation, on the other hand, acts in a more indirect way, showing a more limited effect on social action. The covariance of indignation with compassion is high. This shows that indignation is significant to compassion and guilt, and that conversely they are significant to it. Although its effect on social action is not significantly direct, its presence in the model adds value to it and provides meaning to the mental and behavioral response of the audience.

The beliefs of injustice and immorality have different effects on social action, the former on acts for donation and the latter on social protest. Emphasizing the judgment that poverty and its causes are unjust may help maintain the economic support of donors. These scenarios are based on commitments to the situations that one wants to avoid and transform and not on averse feelings such as guilt. The model tested here presents evidence on how NGDOs can incorporate calls to other types of actions such as social protest by stimulating the judgment of the immorality of the situation.

The results allow us to understand that a moral question is enhanced if accompanied by condemnation of the situation. Similarly, the results seem to suggest the existence of a societal link between moral norms and the activation of emotions and beliefs. The condemnation generated by the protest scenario has an immediate explanation in the way the 
feeling of individual guilt spreads to collective guilt (Branscombe, 2004; Branscombe, Doosje, \& McGarty, 2002; Wohl \& Branscombe, 2008). As a member of a social group responsible for the suffering of the out-group, the feeling of personal involvement can activate a combination of emotional and cognitive averse responses in which the situation that one's own group has generated is rejected.

All in all, the protest scenario better reflects the link between the emotional, cognitive and behavioral responses than does the donor scenario. There is a possibility that a response with greater personal involvement may be due to the novelty of the message. In both scenarios -donor and protest- the moral problem is the same: to prevent widespread suffering of distant and anonymous third parties. When we have to help someone physically close to us, the result of the help is immediately evident. However, in social group problems, the help offered does not result in direct positive reinforcement. The experience of repeated donations is often accompanied by the perception that the donation does not fulfill its purpose. This leads to the feeling that the help offered does not produce the desired outcomes, which results in the aforementioned "compassion fatigue" and "crisis of pity." The protest scenario may have a more significant emotional response due to the absence of repeated experience. The public is used to the donor scenario. A message of condemnation is much less familiar, and the receivers are not ready to respond by distancing themselves from the problem. The importance of this result of moral helping may affect moral judgment and the associated moral response (moral sensitivity). The results of this study suggest that familiarity may explain the lack of commitment to social help messages (Vestergaard, 2008). This outcome opens up new paths for research on the efficacy of the communication of NGDOs in relation to innovative protest models as an alternative to the traditional aid messages to which donors are more accustomed. 


\section{Conclusions}

Why does presenting a situation as condemnable, rather than as a situation of suffering, arouse moral sensitivity? In this case, the agent has a personal engagement with injustice and immorality, whereas his or her participation with poverty is impersonal. The two scenario types analyzed in this paper vary in one aspect or another in their emphasis on the response from the receiver. The donor scenario focuses on suffering caused by poverty, while the protest scenario highlights the social condemnation of unjust behaviors and decisions that have caused suffering and poverty. Our results suggest that when help is motivated by suffering, without condemnation, we do not judge the injustice and/or immorality of widespread poverty in the same way. When condemnation is present, we judge injustice and/or immorality more severely and are more willing to undertake actions of protest, without this affecting our willingness to make a donation. The protest scenario brings the collective problem closer to the donor and triggers his or her motivation to act based on these emotions. We therefore consider that these results contribute further evidence to the key role of emotion and condemnation beliefs in raising moral sensitivity to collective problems.

The proposed model for raising moral sensitivity has shown that it can be the basis for generating communication strategies that actively engage civil society better, not only in its behavior, but also regarding all of the motivational elements involved in the perception of poverty (emotions and beliefs). Due to the fact that society has repeatedly been faced with the image of poverty as pity and assistance and has been educated in a culture of charity (Smith, 2004a, p. 661), the correlations of the variables of the study are not as significant as expected. Receivers do not have the tools to relate to these messages of condemnation designed from a political pedagogy model for public engagement with poverty, a main advocacy liability of NGDOs. 


\section{Limitations}

The present research faces certain limitations regarding its sample and design that we need to acknowledge as they affect its generalizability.

This study used a sample of university students. There exists the possibility that the students perceive and receive collective help messages in a different way, which may affect the study's general application to other audiences. The model should be applied to different samples in order to analyze the possibilities of its replication and generalization to a broader audience. In such an experiment, it would be desirable to incorporate other variables such as gender, age, race, nation, political beliefs or cultural and educational backgrounds and combine different samples to be able to compare the results to other groups and contexts.

A second limitation lies in the fact that this study has been developed with regards to the single context of poverty. It would be interesting to apply it to other contexts (such as altruism, environmentalism or social movements) to again test its generalizability. In addition, the results of this study can be applied in longitudinal studies in order to show how the answers to the different messages evolve depending on the familiarity of the sample with each of the scenarios.

Another particularity of this study has been the use of single-items. According to psychometric theory, this sort of measuring complicates the assessment of constructs. The most conventional strategy is to use multi-item measures that meet the theoretical meaning evaluated. Nonetheless, as an exploratory innovative study, we chose the clarity of single-item to make it easier to apply the same model to other research contexts in future stages of the study. Additionally, we designed this study to investigate the direct response to a particular message. We used single-items to facilitate this direct response from the participants. On the contrary, multi-item measures should be used to asses a theoretical construct. 
Finally, regarding the methodological design, there are limitations regarding our choice of questionnaires (in a self-report format) because social desirability can influence the answers of the survey respondent. For further research, it is necessary to incorporate behavioral measures to assess the direct reactions of the sample to the different messages.

\section{Future research}

The present research focuses centrally on the emotion of guilt and its effects on social action. Future research could focus more specifically on the interaction among other social emotions, such as indignation, in order to strengthen its effects on communication. Such research would foster not only the most characteristic social action (donation), but also other actions such as protest. In this way, it would be possible to assess more accurately whether when guilt, compassion and indignation (together with other emotions of condemnation) have an outstanding presence, they constitute a factor with direct effect on beliefs and/or social action.

As we have already advanced in the discussion, we suggest that future research might take up two different paths to provide deeper insight into these results. On the one hand, we advocate further development of the moral sensitivity model to combine advocacy and funding goals. Such communication scenarios link condemnation to the need of funds in order to work on eradicating poverty through concomitant models. On the other hand, it is necessary to provide a more in-depth analysis of the efficacy of moral sensitivity. This would require testing whether or not once individuals feel motivated to act in response to the campaigns of NGDOs they actually do something in order to transform those perceived injustices. 
Finally, protest scenarios based on indignation are on the rise, not from NGDOs, but from other civil society agents. Therefore, present-day civil society indignant movements around the world make further research in this area timely and urgent.

\section{Notes}

1. The moral condition of social helping is twofold, as is the potentially underlying emotional response. First, it implies the moral rule of wanting to alleviate the suffering caused by poverty, which may be accompanied by the emotion of wanting to alleviate suffering (compassion). Second, it implies the moral rule of preventing or condemning the conditions that generate and perpetuate poverty, which may be accompanied by a moral emotion of condemnation (like indignation). In both cases, the underlying emotions will be associated with the perceived injustice of the harm caused and with the perceived immorality for not helping to eradicate it. The judgment that a moral rule, like social justice, has been violated is associated with a negative emotional response (Greene et al, 2001; Greene, 2003; Haidt, 2002; Prinz, 2007). Although there is no consensus on whether the judgment triggers the emotion or vice versa, both are concomitant in the presence of a moral dilemma. In cognitive terms, deciding whether or not to help involves two judgments: first, whether it is morally acceptable to help in order to alleviate the suffering of a distant, anonymous other, and second, whether it is morally acceptable to maintain the conditions that cause the suffering of the other.

2. When the recipients of the message make a judgment, they are responding to it rationally, beyond the behavioral response that the message itself might elicit. This presumes that motivation is required to process the content of the message. If the processed content establishes a moral judgment, implying that a moral rule has been violated, then there will be an increased likelihood of the person evaluating this violation and concluding that it is wrong. 
When an action is perceived as wrong, a concomitant socio-emotional response occurs that motivates a judgment of condemnation to make amends for the injustice of the wrongdoing (Greene et al., 2001).

3. Following the recommendations of Bentler and Chou (1987), a ratio of 10 participants for each free parameter in the model is required for the results to be considered reliable in a confirmatory factor analysis. The sample was therefore sufficient.

\section{Acknowledgments}

The authors thank the researchers of the Interuniversity Research Institute of Social Development and Peace (IUDESP-UJI) for their feedback on the article and especially Dr. Jennifer Murphy for carefully reviewing and editing the American English of the article.

\section{Funding}

This work is supported by the Spanish State Secretary of Research, Development and Innovation of the Spanish Ministry of Economy and Competitiveness through the research project "Evaluation model and indicators of moral sensitivity in the communication of social movements" (CSO2012-34066). 


\section{References}

Barret, P. (2007). Structural equation modelling. Adjudging model fit. Personality and Individual Differences, 42(5), 815-824.

Basil, D. Z., Ridgway, N. M., \& Basil, M. D. (2006). Guilt appeals: The mediating effect of responsibility. Psychology \& Marketing, 23, 1035-1054.

Basil, D. Z., Ridgway, N. M., \& Basil, M. D. (2008). Guilt and giving: A process model of empathy and efficacy. Psychology \& Marketing, 25(1), 1-23.

Batson, C. et al. (1995). Immorality from empathy-induced altruism: when compassion and justice conflict. Journal Personality and Social Psychology, 68, 1042-1054.

Benthall, J. (2010). Disasters, relief and the media (1st ed. 1993). Wantage: Sean Kingston Publishing.

Bentler, P. M. \& Bonnet, D. C. (1980). Significance tests and goodness of fit in the analysis of covariance structures. Psychological Bulletin, 88 (3), 588-606.

Bentler, P. M., \& Chou, C-P. (1987). Practical issues in structural modelling. Sociological Methods Research, 16, 78-117.

Black, M. (1992). A cause for our times. Oxfam the first 50 years. Oxford: Oxfam.

Boltanski, L. (1999). Distant suffering: Morality, media and politics. Cambridge: Cambridge University Press.

CONCORD (2004). Resolution on development education and awareness. General Assembly. Retrieved March 12 $2^{\text {th }}, 2013$, from http://www.deeep.org/whatisde.html

CONCORD (2007). Code of conduct on images and messages. Retrieved March $12^{\text {th }}, 2013$, from

http://www.deeep.org/images/stories/DARE/CodeofConduct/code $\% 20$ of $\% 20$ conduct $\% 20$ on $\% 20$ messages $\% 20$ and $\% 20$ images.pdf 
Darnton, A. \& Kirk, M. (2011). Finding Frames: New ways to engage the UK public in global poverty. Bond for International Development. Retrieved March 12 , 2013, from http://www.findingframes.org/Finding $\% 20$ Frames $\% 20$ New $\% 20$ ways $\% 20$ to $\% 20$ engage $\%$ 20the\%20UK\%20public\%20in\%20global\%20poverty\%20Bond\%202011.pdf

Davidson, R. J., \& Harrington, A. (eds.) (2002). Visions of Compassion: Western Scientists and Tibetan Buddhists Examine Human Nature. New York: Oxford University Press.

Deacon D. (1999). Charitable Images: the construction of voluntary sector news. In B. Franklin (Ed.) (1999), Social Policy, the Media and Misrepresentation (pp. 51-68). London: Routledge.

Development Education Exchange in Europe Project (DEEEP) (2006). Code of Conduct: Images and Messages relating to the Third World. Retrieved March $12^{\text {th }}, 2013$, from www.deeep.org/codeofconduct.html

Dogra, N. (2007). Reading NGOs Visually - Implications of visual images for NGO management. Journal of International Development, 19, 161-171.

Eade, D., \& Williams, S. (1995). The Oxfam Handbook of Development and Relief, 2. Oxford: Oxfam.

General Assembly of European NGOs (1989). Code of conduct on Messages and Images. Retrieved March 12 $2^{\text {th }}, 2013$, from http://www.deeep.org/code-of-conduct.html

Greene, J. D., \& Haidt, J. (2002). How (and where) does moral judgment work? Trends in Cognitive Sciences, 6(12), 517-523.

Haidt, T. J. (2001). The emotional dog and its rational tail: A social intuitionist approach to moral judgment. Psychological Review, 108, 814-834.

Haid, T. J. (2003). The moral emotions. In R. J. Davidson, K. Scherer \& H. Goldsmith (Eds.), Handbook of Affective Sciences (pp. 852-870). Oxford: Oxford University Press. 
Hall, S. (1997). Representation: Cultural Representations and Signifying Practices. London: Sage Publications.

Hu, L. T., Bentler, P. M., \& Kano, Y. (1992). Can test statistics in covariance structure analysis be trusted? Psychological Bulletin, 112(2), 351-362.

Hu, L. T., \& Bentler, P. M. (1999). Cutoff criteria for fit indexes in covariance structure analysis: Conventional criteria versus new alternatives. Structural Equation Modeling, $6(1), 1-55$.

Jöreskog, K. \& Sörbom, D. (1993). LISREL 8: Structural equation modeling with the SIMPLIS command language. Chicago: Scientific Software International Inc.

Minear, L. (1987). The other mission of NGOs: education and advocacy. World Development, $15,189-200$.

Moeller, S. D. (1999). Compassion fatigue: How the media sell disease, famine, war and death. New York: Routledge.

Moll, J., de Oliveira-Souza, R., Moll, F. T., Ignacio, F. A., Bramati, I. E., Caparelli-Dáquer, E. M., \& Eslinger, P. J. (2005). The moral affiliations of disgust: a functional MRI study. Cognitive Behavioral Neurology, 18 (1), 68-78.

Nos Aldás, E., \& Pinazo, D. (2010). La incógnita de la persuasión en la comunicación de las ONGD: hacia un modelo de publicidad culturalmente eficaz. Industrias da Persuassão (pp. 87-122). Covilhã: Universidade da Beira Interior.

Pinazo, D., Barros-Loscertales, A., Peris, R., Ventura-Campos, N., \& Avila, C. (2012). The role of self-responsibility in the neural response to the supportive communication. International Journal of Nonprofit and Voluntary Sector Marketing, 17, 263-274.

Pope, J. A.; Isely, E. S., \& Asamoa-Tutu, F. (2009). Developing a Marketing Strategy for Nonprofit Organizations: An Exploratory Study. Journal of Nonprofit \& Public Sector Marketing, 21, 184-201. 
Prinz, J. J. (2007). The emotional constructions of morals. Oxford: Oxford University Press.

Rozin, P., Haidt, J., \& McCauley, C. R. (2005). Disgust: The Body and Soul Emotion. In T.

Dalgleish \& M. J. Power (Eds.), Handbook of Cognition and Emotion (pp. 429-445). Chichester: John Wiley \& Sons, Ltd.

Rozin, P., Lowery, L., Imada, S., \& Haidt, J. (1999). The CAD triad hypothesis: A mapping between three moral emotions (contempt, anger, disgust) and three moral codes (community, autonomy, divinity). Journal of Personality and Social Psychology, 76(4), 574-586.

Sen, A (1999). Development as Freedom. Oxford: Oxford University Press.

Silverstone, R. (2008). Media and morality: on the rise of the mediapolis. London: Polity Press.

Smith, M. (2004a). Contradiction and change? NGOs, schools and the public faces of development. Journal of International Development, 16(5).

Smith, M. (2004b). Mediating the world: development, education and global citizenship. Globalisation, Societies and Education, 2(1), 1-24.

Smith, M. (2008). International non-governmental development organizations and their Northern constituencies: development education, dialogue and democracy. Journal of Global Ethics, 4(1), 5-18.

Sogge, D. (1996). Compassion \& Calculation. The Business of Private Foreign Aid. London: Pluto Press/Transnational Institute.

Stürmer, S., Snyder, M., \& Omoto, A. M. (2005). Pro-social emotions and helping: the moderating role of group membership. Journal Personality and Social Psychology, 88, $532-546$. 
Tallon, R. (2008). The image dilemma: the ethics of using images of the poor for fund-raising and awareness campaigns. Paper presented at DevNet. Peripheral Visions. Wellington: Victoria University.

Vestergaard, A. (2008). The case of Amnesty International. Journal of Language and Politics, 7(3), 471-493.

Witteborn, S. (2010). The role of transnational NGOs in promoting global citizenship and globalizing communication practices. Language and intercultural communication, 10(4), $358-372$. 
Table 1. Correlation of the variables of the study

\begin{tabular}{|c|c|c|c|c|c|c|}
\hline & Compassionate & Indignation & Injustice & Immoral & Protest & Donate \\
\hline Guilty & $.20^{* *}$ & $.23^{\star * *}$ & .11 & $.20^{* *}$ & $.25^{\star \star *}$ & $.26^{\star * \star}$ \\
\hline Compassionate & - & $.27^{\star \star *}$ & $.15^{*}$ & $.14^{*}$ & -.02 & .04 \\
\hline Indignation & - & - & $.30^{* * *}$ & $.26^{* \star *}$ & $.20^{* *}$ & $.17^{* *}$ \\
\hline Injustice & - & - & - & $.26^{* * *}$ & $.15^{\star *}$ & $.17^{* *}$ \\
\hline Immoral & - & - & - & - & $26^{\star * *}$ & .10 \\
\hline Protest & - & - & - & - & - & $.30^{* * *}$ \\
\hline
\end{tabular}


Table 2. ANOVA of the emotional, perceptive and behavioral response according to the type of communication scenario $(\mathrm{H} 1, \mathrm{H} 2, \mathrm{H} 3, \mathrm{H} 4, \mathrm{H} 5, \mathrm{H} 6)$

\begin{tabular}{|c|c|c|c|c|}
\hline & $\begin{array}{l}\text { Donor } \\
\text { scenario }\end{array}$ & $\begin{array}{c}\text { Protest } \\
\text { scenario }\end{array}$ & $F$ & $\eta^{2}$ \\
\hline Guilty & $\begin{array}{c}3.12 \\
(1.63)\end{array}$ & $\begin{array}{c}3.08 \\
(1.71)\end{array}$ & .04 & .00 \\
\hline Compassionate $(\mathrm{H} 2)$ & $\begin{array}{c}4.64 \\
(1.63)\end{array}$ & $\begin{array}{c}4.79 \\
(1.63)\end{array}$ & .65 & .00 \\
\hline Indignation $(\mathrm{H} 1)$ & $\begin{array}{l}4.24 \\
(1.77)\end{array}$ & $\begin{array}{l}5.26 \\
(1.56)\end{array}$ & $27.05^{\star * \star}$ & .09 \\
\hline Injustice (H4) & $\begin{array}{c}5.61 \\
(1.66)\end{array}$ & $\begin{array}{c}6.28 \\
(1.11)\end{array}$ & $16.43^{* \star *}$ & .05 \\
\hline Immoral $(\mathrm{H} 3)$ & $\begin{array}{c}5.27 \\
(1.52)\end{array}$ & $\begin{array}{c}5.89 \\
(1.32)\end{array}$ & $13.88^{* * *}$ & .05 \\
\hline $\begin{array}{l}\text { Protest (participation in } \\
\text { demonstrations, sign } \\
\text { petitions for action) }(\mathrm{H} 6)\end{array}$ & $\begin{array}{c}3.61 \\
(1.87)\end{array}$ & $\begin{array}{c}4.41 \\
(3.63)\end{array}$ & $5.36^{*}$ & .02 \\
\hline Donate money $(\mathrm{H} 5)$ & $\begin{array}{l}3.90 \\
(2.17)\end{array}$ & $\begin{array}{c}3.59 \\
(2.21)\end{array}$ & 1.48 & .00 \\
\hline
\end{tabular}




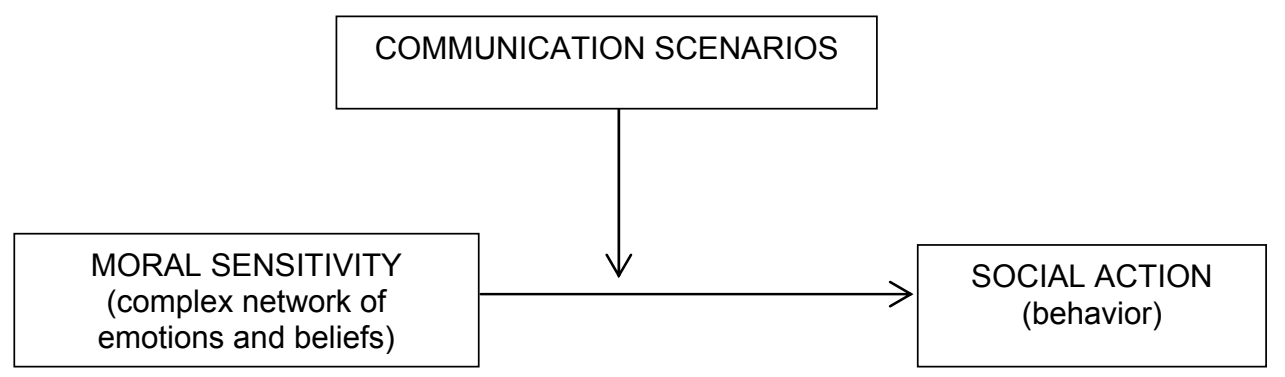

Figure 1. Communication Model 


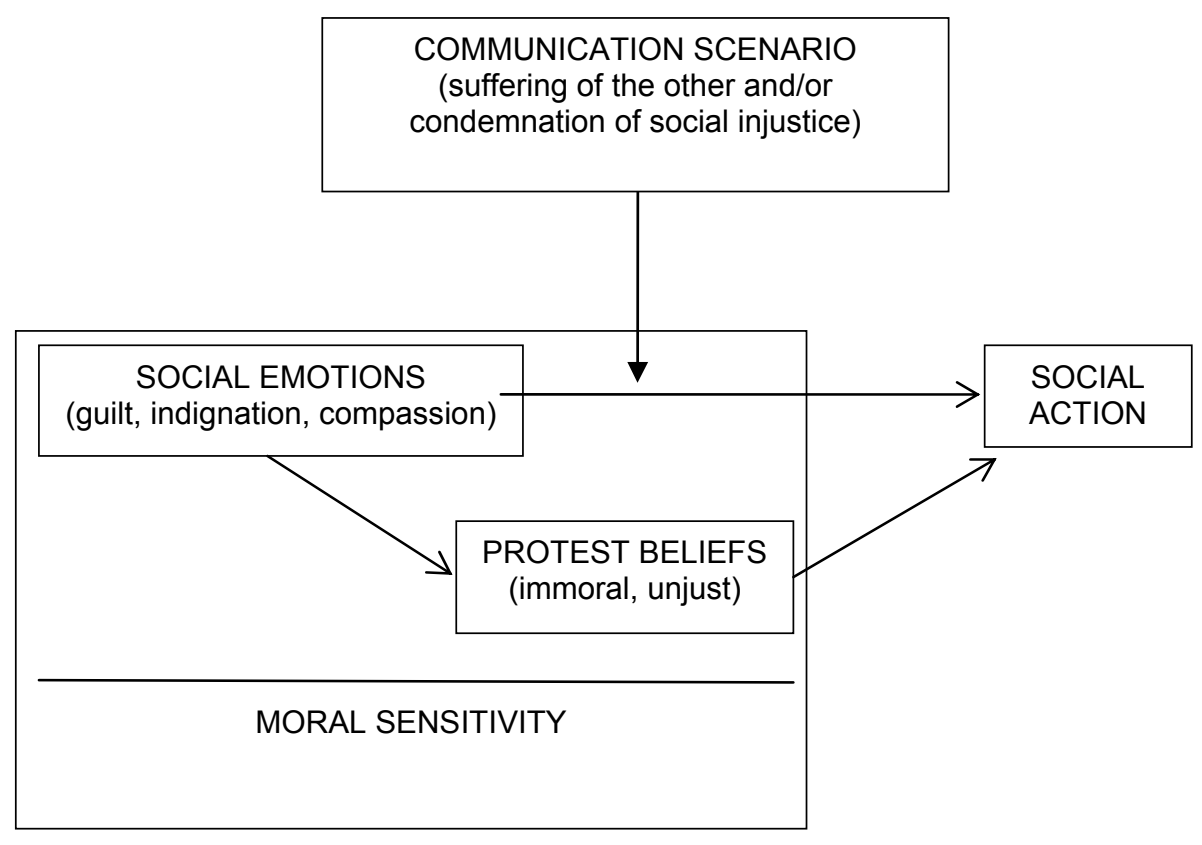

Figure 2. Communication Model based on Moral Sensitivity 


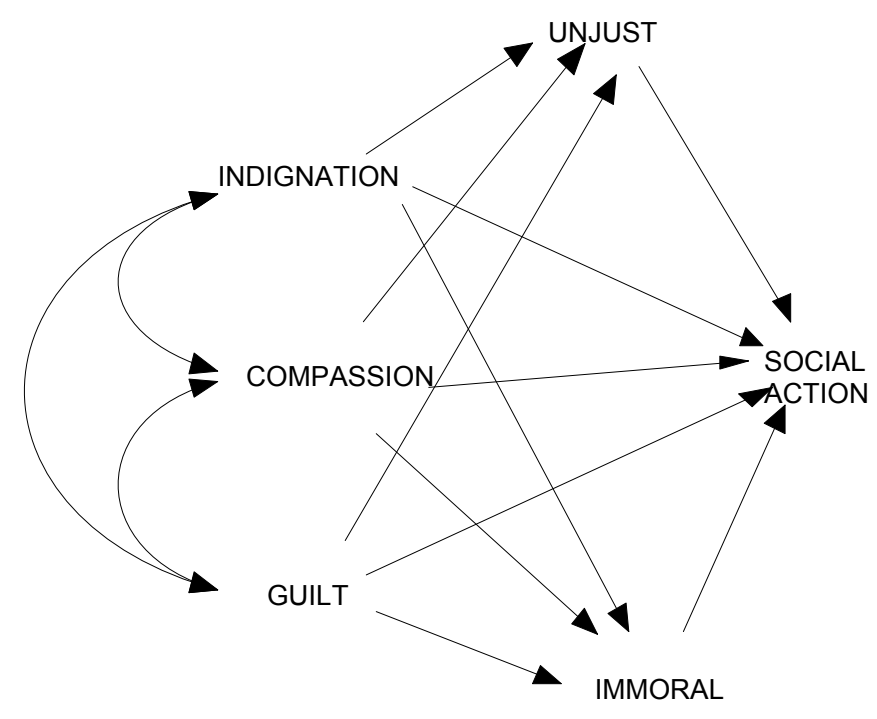

Figure 3. Tested effect model Communication Scenarios 


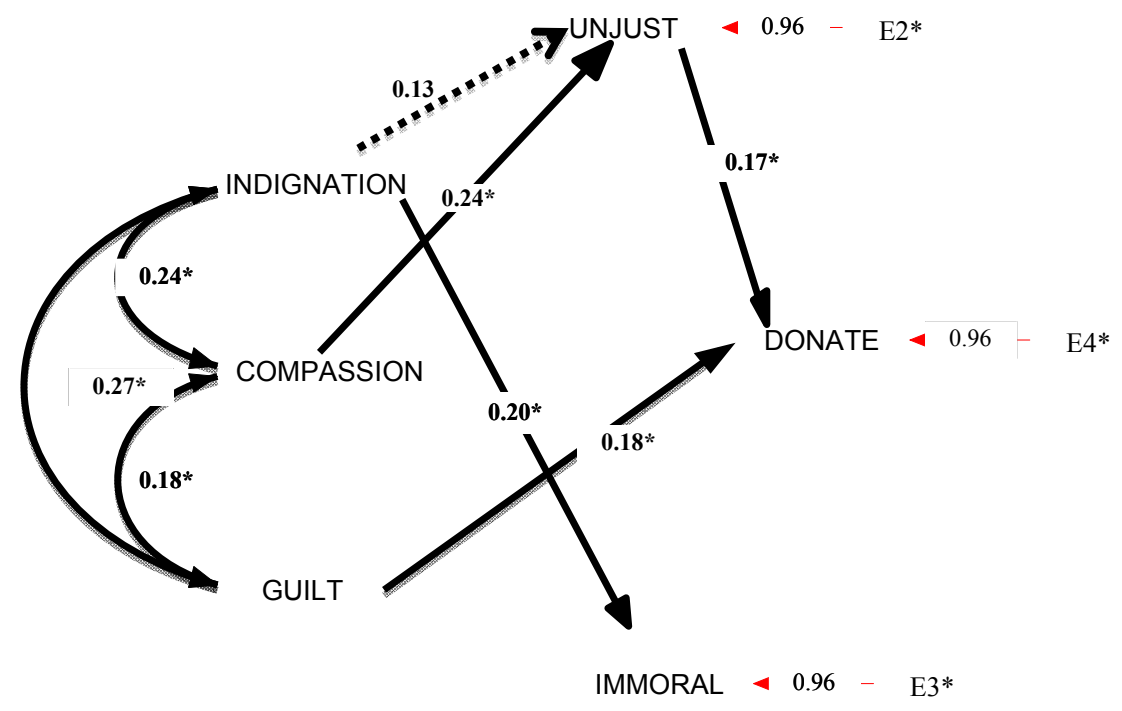

Figure 4. Tested effect model Protest Scenario for the action of donating ${ }^{*} p<.05$ _close to the standard range of significance 


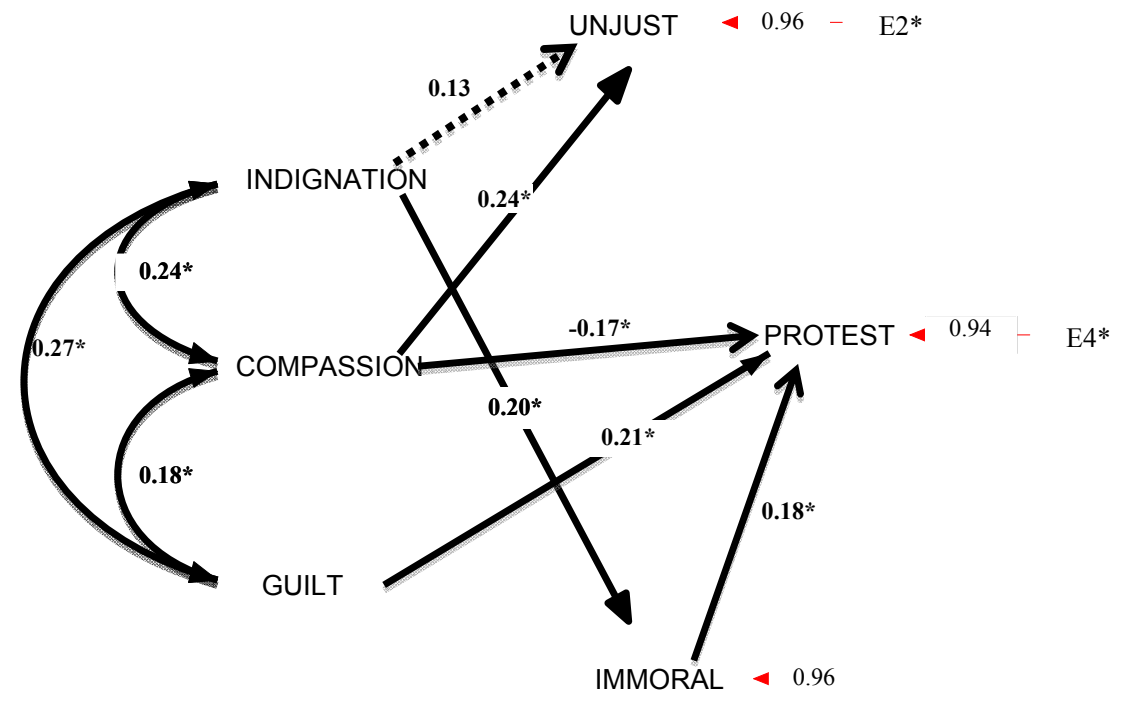

Figure 5. Tested effect model Protest Scenario for protest action ${ }^{*} p<.05$ _ close to the standard range of significance 
Appendix 1. Translated scripts and frequency of response to each script in the behavioral study Donor Group
Message A
D1. Thousands of people urgently need help to survive. They do not have enough food or water,
or any way of getting them for themselves. They are victims of war in their countries. With your
help we can save women and children, victims of armed conflicts, from hunger. Make a donation
to our NGO!
D2. Thousands of people urgently need help to survive. With your help we can halve the number
of people living on less than one euro a day. Help us to get rid of extreme poverty and hunger.
Make a donation to our NGO!
D3. Thousands of people urgently need help to survive. Just $€ 12$ a month can provide 125
vaccinations against measles, an illness that causes infant deaths in countries with no resources.
This is only one example of how you can help us to help them. Make a donation to our NGO!
D4. Thousands of people urgently need help to survive. With your help, the number of children
registered in primary schools in the developing regions where we have been active has increased
by $80 \%$. Our target is to achieve universal primary education. Make a donation to our NGO!
D5. Thousands of people urgently need help to survive. Official calculations show that 10 million
African children die every year from causes that can be prevented before they reach their fifth
birthday. With your help, we can give them the medicines they need. Make a donation to our
NGO!
D6. Thousands of people urgently need help to survive. With your help, we can provide the
medical assistance they need. With $€ 10$ a year, we can send a full surgical team to a country at
war or we can vaccinate 400 children against meningitis. Make a donation to our NGO!
$\mathrm{N}$

P1. It is unjust and outrageous. Our companies employ children in Laos to manufacture cheap tennis shoes. These children have to work for paltry wages in order to eat. Just 36 cents more would enable them to go to school and stop working. And we say nothing. Break that silence. Protest!

P2. It is unjust and outrageous. African children are working for our Western companies, picking cocoa beans to make chocolate. Our companies treat them like slaves; they pay them nothing, so we can buy their products at a cheap price. And we say nothing. Break that silence. Protest! P3. It is unjust and outrageous. The mineral resources in African countries belong to our Western companies. Instead of using them to create employment and wealth in the country, our companies hire armies to guarantee their slave labor and cheap prices. And we say nothing. Break that silence. Protest!

P4. It is unjust and outrageous. Our companies pay women workers in China one euro for a 15hour shift. They cannot take a day off, and they have no social security. These women pay for their food and to sleep in the factory. Break the silence. Protest!

P5. It is unjust and outrageous. The multinational oil companies hire armies and bribe governments so they can destroy the livelihood of millions of people living on the lands they want to exploit. And we say nothing. Break that silence. Protest!

P6. It is unjust and outrageous. Sports equipment companies spend their money on advertising and design. They keep thousands of workers in subhuman conditions, but they are not prepared to spend one cent to provide decent working conditions in their production plants. Break the silence, protest!

TOTAL 
Appendix 2. Translation of the questionnaire (sample)

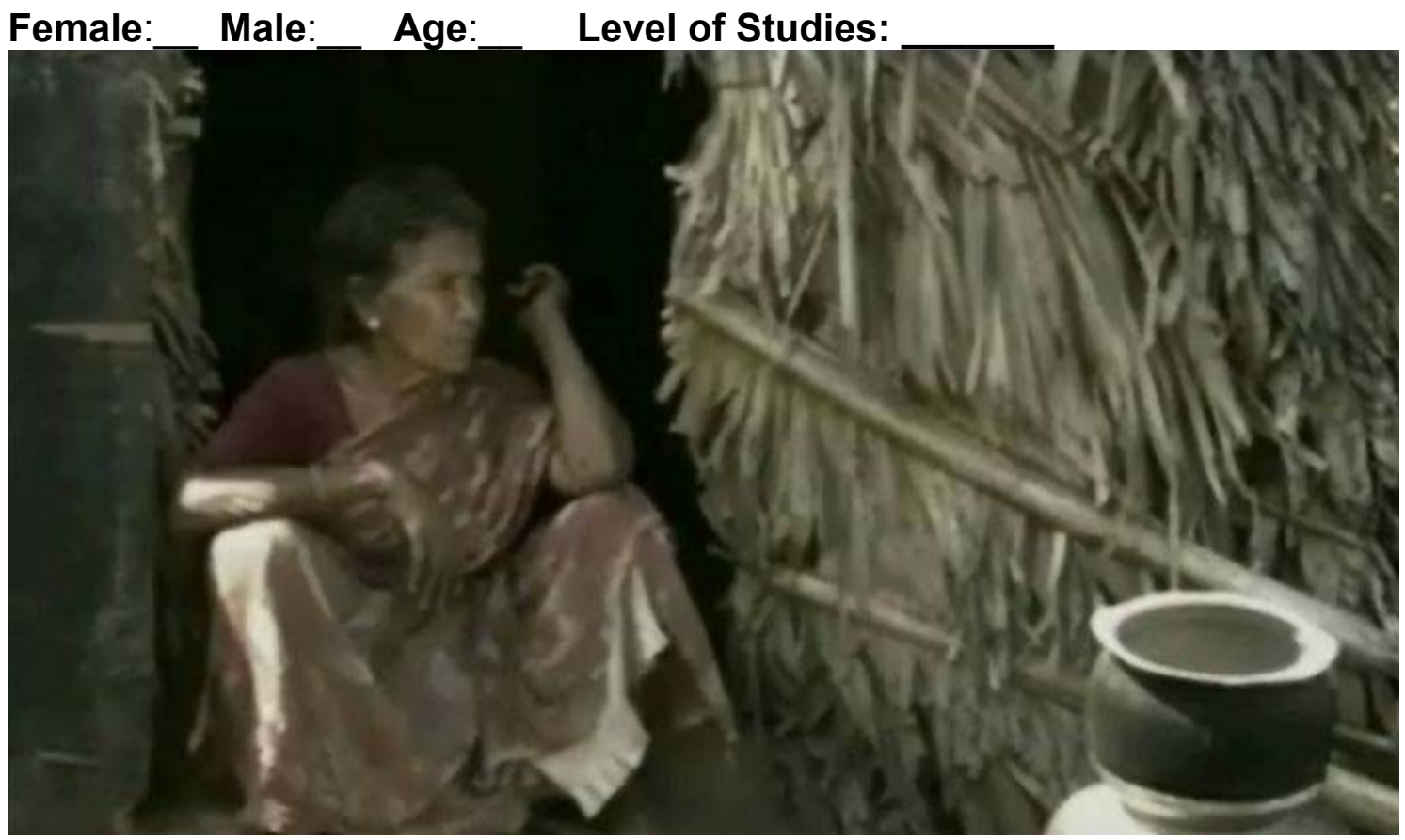

[In this space one of the donor o protest scripts where inserted. For example: P1. It is unjust and outrageous. Our companies employ children in Laos to manufacture cheap tennis shoes. These children have to work for paltry wages in order to eat. Just 36 cents more would enable them to go to school and stop working. And we say nothing. Break that silence. Protest!

\begin{tabular}{|c|c|c|c|c|c|}
\hline How do you feel about the situation? & $\begin{array}{l}\text { WHEN FA } \\
\text { FEEL.... }\end{array}$ & NG & $\mathbf{A T}$ & & ON I \\
\hline \multirow[b]{2}{*}{ Compassionate } & \multicolumn{3}{|l|}{ NOTHING } & \multicolumn{2}{|r|}{ A LOT } \\
\hline & $1 \quad 2$ & 3 & 4 & 5 & 67 \\
\hline \multirow[b]{2}{*}{ Guilty } & NOTHING & & & \multicolumn{2}{|r|}{ A LOT } \\
\hline & $1 \quad 2$ & 3 & 4 & 5 & $6 \quad 7$ \\
\hline \multirow[b]{2}{*}{ Indignant } & NOTHING & & & \multicolumn{2}{|r|}{ A LOT } \\
\hline & $1 \quad 2$ & 3 & 4 & 5 & $\begin{array}{ll}6 & 7\end{array}$ \\
\hline
\end{tabular}

\begin{tabular}{|l|llllllc|}
\hline \hline $\begin{array}{l}\text { Do you think it is immoral not to help eradicate } \\
\text { world poverty? }\end{array}$ & $\begin{array}{l}\text { NO } \\
1\end{array}$ & 2 & 3 & 4 & 5 & 6 & $\begin{array}{c}\text { YES } \\
7\end{array}$ \\
\hline $\begin{array}{l}\text { Do you think it is a social injustice that poverty } \\
\text { exists in the world? }\end{array}$ & $\begin{array}{l}\text { NO } \\
1\end{array}$ & 2 & 3 & 4 & 5 & 6 & 7 \\
\hline
\end{tabular}

\begin{tabular}{|c|c|c|c|c|c|}
\hline $\begin{array}{l}\text { WHEN FACING THE SITUATION YOU HAVE } \\
\text { JUST READ, ARE YOU WILLING TO...? }\end{array}$ & & & & & \\
\hline Donate to an NGO & $\begin{array}{l}\mathrm{NO} \\
1 \quad 2\end{array}$ & 3 & & & ( \\
\hline Collaborate in protest actions organized by an NGO & $\begin{array}{l}\mathrm{NO} \\
1 \quad 2\end{array}$ & 3 & & & \\
\hline
\end{tabular}


Contact information:

Daniel Pinazo Calatayud / Eloísa Nos Aldás

Facultad de Ciencias Humanas y Sociales

Avda. SOS BAYNAT, S/N,

UNIVERSITAT JAUME I,

CASTELLÓN, SPAIN

Postal code 12071

Brief biographical statement:

Daniel Pinazo, PhD in Social Psychology. Tenured lecturer at the Universitat Jaume I (Castellón, Spain). He is a research member of the Research Groups "Social Development \& Peace" and "Corporate Social Responsibility" and of the Interuniversity Research Institute in Social Development \& Peace (IUDESP-UJI) at the same university.

Eloísa Nos, $\mathrm{PhD}$ in Communication. Tenured lecturer at the Communication Sciences Department at the Universitat Jaume I (Castellón, Spain). She is the Head of the Interuniversity Research Institute in Social Development \& Peace (IUDESP-UJI) at the same university.

www.iudesp.uji.es

Acknowledgments

The authors thank the researchers of the Interuniversity Research Institute of Social

Development and Peace (IUDESP-UJI) for their feedback on the article and especially Dr.

Jennifer Murphy for carefully reviewing and editing the American English of the article. 